[CONTRIBUTION FROM THE CHEMICAL LABORATORY OF WASHINGTON UNIVERSiTY.]

\title{
ON THE PREPARATION OF FUMARIC NITRILE. THE ACTION OF HYDROXYLAMINE ON FUMARIC NITRILE.
}

By I. MCMaster and F. B. Langreck.

Recejved March 21, 1918.

The nitrile ${ }^{1}$ of fumaric acid was prepared some years ago in this laboratory by heating fumaramide with phosphorus pentoxide, but the yield was very small. The constitution ${ }^{2}$ of this nitrile was established by transforming it back into fumaramide and fumaric acid.

To inquire further into the methods of preparation and the properties of this nitrile is the purpose of this work. At first, experiments were made to improve the methods of making the nitrile and then the action of hydroxylamine upon it was studied.

\section{Preparation from Fumaramide.}

Preparation of Methyl Fumarate.-Twenty g. of pure fumàric acid was dissolved in $120 \mathrm{cc}$. of absolute methyl alcohol and the solution boiled for 8 hours on the water bath. During the heating a stream of dry hydrogen chloride was passed through the solution. After cooling, the contents of the flask practically solidified. The mass was broken up and the crystals of dimethyl fumarate were filtered off on a suction filter. They were washed with $10 \mathrm{cc}$. of ice-cold alcohol and dried by drawing air through them while on the filter. Yield, $19.5 \mathrm{~g}$. of large, white, glistening leaves; $m$. p. $102^{\circ}$. The recorded ${ }^{3} \mathrm{~m}$. p. is $102^{\circ}$. This method was found to give the best yield of several tried. The alcoholic filtrate was evaporated to about $50 \mathrm{cc}$. and a second crop of crystals obtained. These, however, required a recrystallization from hot methyl alcohol to rid them of a yellowish color.

Preparation of Fumaramide.-Nine g. of the dimethyl fumarate was treated with $35 \mathrm{cc}$. of ammonia water, sp. gr. 0.90 . The mixture was placed in a flask and allowed to stand, with occasional shaking, for 24 hours. ${ }^{4}$ The fumaramide formed as a fine, white powder. It was filtered off, dried on the filter and then heated in an air bath at $110^{\circ}$. The filtrate, containing some unchanged ester, was saturated in the cold with ammonia gas and allowed to stand for 24 hours, whereupon further formation of the amide took place. The total yield was $6.2 \mathrm{~g}$. of fumaramide which melted, after carbonizing, at $266^{\circ}$.

Preparation of the Nitrile.-Keiser and Kessler ${ }^{5}$ obtained a yield of $0.15 \mathrm{~g}$. of nitrile $(5.6 \%$ of theory), by heating $5 \mathrm{~g}$. of fumaramide with

1 Keiser and Kessler, Am. Chem. J., 46, $5^{23}$ (191 I).

${ }^{2}$ Keiser and McMaster, Ibid., 49, 81 (1913).

${ }^{3}$ Anschütz, Ber., 12, 2282 (1879).

"See Hagen, Ann., 38, 275 (1841).

${ }^{B}$ Loc. cit. 
I $5 \mathrm{~g}$. of phosphorus pentoxide to $\mathrm{I} 20^{\circ}$ in a crystallizing dish, covered with a cool funnel, on the walls of which the sublimate of nitrile condensed. This method was repeated a number of times, and the best yield we could obtain from $5 \mathrm{~g}$. of amide was $0.16 \mathrm{~g}$. of nitrile (6\% of theory).

We then carried out the reaction in a retort and passed a current of dry air over the mixture to carry away the nitrile as fast as it was formed. A water-cooled condenser was substituted for the funnels. The retort was heated to $170^{\circ}$ in an oil bath. Experiments, using $3 \mathrm{~g}$. of fumaramide, gave yields of nitrile that varied from $\mathrm{I} 2$ to $15 \%$ of theoretical. It was now decided to carry out the reaction in the presence of dry nitrogen instead of air. The nitrogen was prepared from air by means of Van Brundt's ${ }^{1}$ apparatus. $25 \%$ yields of the nitrile were thus obtained.

Attempts were made to prepare the nitrile by heating zinc fumarate with lead, barium and potassium thiocyanates but no yields could be obtained.

We also carried out experiments in an attempt to prepare, the amide and nitrile of maleic acid. While our work on these compounds has been very much more extended than that ${ }^{2}$ previously done in this laboratory, the results were not satisfactory.

\section{The Action of Hydroxylamine on Fumaric Nitrile.}

Fumaric nitrile, being a dinitrile, should yield a diamidoxime when treated with hydroxylamine according to the equation<smiles>N#C/C=C\C#N</smiles>

Preparation.-One g. of fumaric nitrile was treated with $\mathrm{I} .77 \mathrm{~g}$. of hydroxylamine hydrochloride and I.36 g. of sodium carbonate, dissolved in $20 \mathrm{cc}$. of water. After the evolution of carbon dioxide had ceased, a clear solution resulted. The mixture was allowed to stand I $_{5}$ hours, at the end of which time a bulky, white mass had separated out of solution. After filtering, this white mass was recrystallized from hot water and formed as fine, white needles. They melted sharply, with carbonization, at $212^{\circ}$. At temperatures below $22_{2}^{\circ}$, the crystals slowly blackened and it was necessary to make the determination by plunging the $\mathrm{m}$. $\mathrm{p}$. tube into sulfuric acid at or near $212^{\circ}$. Yield, $0.32 \mathrm{~g}$. This procedure was repeated a number of times.

Properties.-The substance is fairly soluble in cold water and very soluble in hot water, from which it crystallizes as slender, sparkling needles. It is insoluble in ether and cold ethyl alcohol, and but slightly soluble in

1 This Journal, 36, 1448 (I9I4).

${ }^{2}$ Keiser and McMaster, Am. Chem. J., 49, 8I (I9I3). 
hot alcohol. It is insoluble in chloroform and acetone and readily soluble in glacial acetic acid.

The aqueous solution gives no precipitate with potassium chromate or picric acid solutions. It gives a deep red color with ferric chloride solution, which is characteristic of amidoximes. Bromine water and alkaline potassium permanganate solution are rapidly decolorized by the aqueous solution. Silver nitrate solution precipitates a white salt from the aqueous solution. This salt, when heated, deflagrates and leaves a residue of silver.

Dry hydrogen chloride passed into the glacial acetic acid solution of the compound precipitates a white substance which is very soluble in water. This precipitate melts at $2 \mathrm{I}^{\circ}$, hydrochloric acid being split off during the heating. Evidently the hydrochloride of the original compound had been formed.

Boiling the compound with water for 20 hours failed to transform it into fumaramide, as was expected.

Analysis. - If the compound is the diamidoxime and has the formula $\mathrm{C}_{4} \mathrm{H}_{8} \mathrm{~N}_{4} \mathrm{O}_{2}$, it should contain $38.89 \% \mathrm{~N}, 33.31 \% \mathrm{C}$ and $5.60 \% \mathrm{H}$. We made 5 determinations of carbon and 6 of hydrogen, each of which agreed quite well with the figures just given. We made 6 determinations of $\mathrm{N}$, the results varying from $30.25 \%$ to $33.33 \%$. The determinations were made by all the different modifications of the Kjeldahl method. Since we could obtain no check results by the Kjeldahl method, determinations of the amount of nitrogen were made by the Dumas method, which proved to be successful.

Calc. for $\mathrm{C}_{4} \mathrm{H}_{8} \mathrm{~N}_{4} \mathrm{O}_{2}$ : C, 33.3I; H, 5.60; N, 38.89. Found: C, 33.43 (average of 5 determinations); H, 5.95 (average of 6 determinations); N, 38.55 and $38.5 \mathrm{I}$.

Our results of analysis check quite closely with those calculated for the diamidoxime. The compound has the solubilities in the different organic solvents characteristic of amidoximes. The other reactions mentioned are also those characteristic of amidoximes. We, therefore, are of the opinion that the new compound prepared by treating fumaric nitrile with hydroxylamine is fumardiamidoxime and has the formula given above.

If, after removing the white mass of fumardiamidoxime first formed in the reaction, we extract the filtrate with ether, there is obtained from the ether extract a yellow cotton-like substance which rapidly darkens when exposed to the air. It melts, with carbonization, at $105^{\circ}$. Analysis showed it to consist of $43.70 \% \mathrm{C}, 6.49 \% \mathrm{H}$ and $25.61 \% \mathrm{~N}$.

\section{Summary.}

The method of preparation of fumaric nitrile by the action of phosphorus pentoxide on fumaramide has been improved. $25 \%$ yields, in contrast to former $6 \%$ yields, have been obtained. 
The action of hydroxylamine upon furmaric nitrile has been studied and we have prepared the diamidoxime of fumaric acid. Its properties are described.

Sr. Lours, Mo.

[Contribution from the Kent Chemical laboratory, University of Chicago.]

\section{THE OXIDATION OF MALTOSE IN ALKALINE SOLUTION BY HYDROGEN PEROXIDE AND BY AIR. THE PREPARATION 'AND STUDY OF MALTOBIONIC ACID.}

By J. W. E. Glattheld and Milton T. Hanke, ${ }^{1}$

Received March 25, 1918.

The work reported in this paper was begun under the direction of the late Dr. Nef and was part of the program laid out by him for solving the problem of the mechanism of the oxidation of sugars in alkaline solution. His theory of this mechanism has already been published $^{2}$ and consists, in part, of the assumptions that $1,2-, 2,3$ - and 3,4-di-enols, $i$. e., $\mathrm{CH}_{2} \mathrm{OH}-\mathrm{CHOH}-\mathrm{CHOH}-\mathrm{COH}=\mathrm{COH}-\mathrm{CH}_{2} \mathrm{OH}$ (2,3-di-enol), are formed from the ordinary hexoses under these conditions, and that these di-enols later break at the double bonds giving rise to methyleneenols which undergo oxidation to produce acids. To ascertain whether the same theory, which has proved adequate for the ordinary hexoses, also applies to oxidation of the disaccharides, the oxidation of maltose here reported, was undertaken. The results are in complete harmony with the theory as far as it was possible for us to determine. That is, the presence of the oxidation products here reported can be explained by assuming that the "free" glucose unit of maltose is first enolized and the enols, after breaking, either become oxidized at once or undergo certain rearrangements with or without subsequent oxidation. An unexpected development was the discovery that a $\mathrm{C}_{4}$-saccharinic acid was present in the oxidation mixture in the case of the oxidation with air. Up to the time of the work here reported only aldonic acids, $i$. e., acids obtained by oxidizing the aldehyde group of aldo-monosaccharides directly to the carboxyl group, had been found in the reaction mixtures obtained in the oxidation experiments with the sugars in alkaline solutions. A1though unexpected, the presence of a saccharinic acid is not unexplainable. It is well known that saccharinic acids are formed by the action of alkalies on sugar' in the absence of an oxidizing agent. ${ }^{3}$ It is therefore, quite conceivable that such acids should be formed during the oxida-

1. The dissertation, of which this paper is a condensation, was presented by Milton $T$. Hanke as part fulfillment of the requirements for the degree of Doctor of Philosophy in the University of Chicago.

${ }^{2}$ Am. Chem. J., 50, 137 (I9I3).

3Ann., 376, I-I20 (I9ro). 